\title{
Flame Spread Monitoring and Estimation of the Heat Release Rate from a Cable Tray Fire using Video Fire Analysis (VFA)
}

\author{
First Author · Second Author
}

Received: date / Accepted: date

\begin{abstract}
The paper presents an application of Video Fire Analysis (VFA) to a cable tray fire scenario, a scenario of interest to Nuclear Power Plants (NPPs) where cables constitute a substantial part of the combustible load. Five horizontal trays, each $2.4 \mathrm{~m}$ long and $0.45 \mathrm{~m}$ wide, are positioned with a $0.3 \mathrm{~m}$ spacing (in the vertical direction) and set-up against an insulated wall. Each tray contains 49 power PVC cables of $13 \mathrm{~mm}$ outer diameter. Ignition is performed with an $80 \mathrm{~kW}$ propane burner centrally positioned at $0.2 \mathrm{~m}$ below the first (i.e. lowest) tray. Thanks to a flame detection algorithm, the VFA technique allows a reconstruction of the heat release rate (HRR) profile based on the estimated temporal evolution of flame and extinction fronts at the level of each tray. The obtained profile is generally in good agreement with the HRR measurements (from oxygen depletion calorimetry). However, the time to reach the peak HRR is overestimated by approximately $100 \mathrm{~s}$ and the peak HRR of $3 \mathrm{MW}$ is underestimated by $17 \%$. These results are nevertheless encouraging because they provide confidence in the flame spread measurements (which are estimated for the case at hand between 2 and 5 $\mathrm{mm} / \mathrm{s}$ ). Therefore, a systematic application of VFA to real-scale experiments is believed to generate a valuable set of data (e.g. flame spread rates) for the development of simplified modelling.
\end{abstract}

Keywords Cable Fire Spread (CFS) · Video Fire Analysis (VFA)

\author{
F. Author \\ first address \\ Tel.: +123-45-678910 \\ Fax: +123-45-678910 \\ E-mail: fauthor@example.com \\ S. Author \\ second address
}




\section{Introduction}

Fire analysis efforts in Nuclear Power Plants (NPPs) have particularly focused on cable trays because they constitute a substantial part of the combustible load in NPPs. These efforts have resulted in a large set of experimental data that allowed the development of models with several degrees of complexity. However, there is still no consensus on the best approach for the prediction of the heat release rate (HRR) from a stack of cable trays. The methodology suggested in $[2,3]$ for the HRR prediction from a stack of horizontal cable trays, and referred to as the FLASH-CAT model, addresses an overall description of the fire development in the framework of a simplified modelling approach (in comparison for instance to the Computational Fluid Dynamics (CFD) technique). The FLASH-CAT model assumes that, for an ignition below the centre of the lowest tray, the fire produces a V-shaped pattern with a given constant angle and spreads laterally at a constant rate. It is stated nevertheless in [3] that it is difficult to measure experimentally the spreading rate and that there is not enough new data to suggest that the horizontal spread rates used in the simplified approach are inappropriate. The work presented in this paper seeks to fill this gap by applying the Video Fire Analysis (VFA) technique described in [4] to the case of five horizontal trays. The temporal evolutions of flame and extinction fronts are tracked at the level of each tray and estimates of the HRR, flame spread rates and fire development pattern (e.g., flame spread angle) are produced.

\section{Description of the fire scenario}

The experimental test considered in this work has been performed by the French institute IRSN (Institut de Radioprotection et de Sûreté Nucléaire) in the context of two large international collaborative research projects, called PRISME and PRISME 2 [5,6]. The burning behaviour of cable trays in open atmosphere conditions is characterized in [7]. The test considered here is called CFSS1.

The fire source, as shown in Fig. 1, is composed of five horizontal trays $2.4 \mathrm{~m}$ long and $0.45 \mathrm{~m}$ wide, with a $0.3 \mathrm{~m}$ spacing. The trays are set-up against an insulated side wall. Each tray contains 49 power PVC cables of $13 \mathrm{~mm}$ outer diameter provided by one of the PRISME partners, the technical research center of Finland (VTT). Each cable is composed of: (1) a metallic material with a linear mass of $85 \mathrm{~g} / \mathrm{m},(2)$ a sheath layer with a linear mass of 85 $\mathrm{g} / \mathrm{m}$, (3) a filler layer with a linear mass of $35 \mathrm{~g} / \mathrm{m}$, and (4) an insulation layer of $30 \mathrm{~g} / \mathrm{m}$. Chemical analyses have identified mainly three elements in the composition of each cable: $\mathrm{PVC}, \mathrm{CaCO}_{3}$ and phthalates. The ignition source is a sand burner of $0.3 \times 0.3 \mathrm{~m}^{2}$ located $0.2 \mathrm{~m}$ below the first tray at the centre. The gas burner supplied with propane delivers a fire power of 80 $\mathrm{kW}$. The supply is stopped when the total HRR reaches $400 \mathrm{~kW}$. This time is considered as the ignition time of the cable trays. In other words, it is the time 


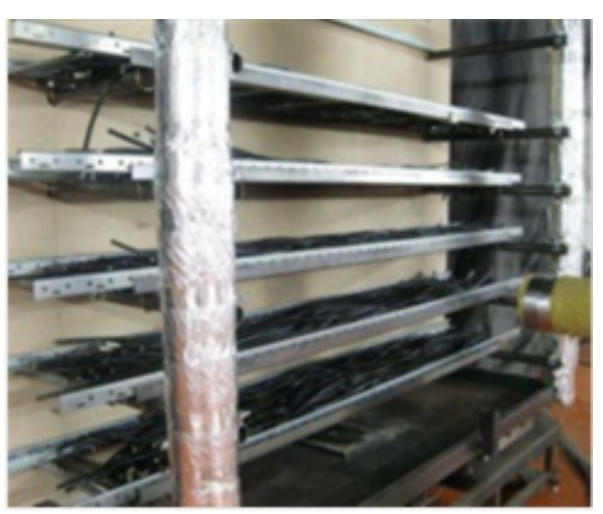

Fig. 1 The five horizontal cable tray device used for the CFSS fire tests

after which self-sustained burning occurs. For the considered test, the ignition time is $80 \mathrm{~s}$.

\section{Application of the VFA technique: Flame spread monitoring and HRR profile reconstruction}

Video Fire Analysis (VFA) consists of analyzing video camera footages from a fire scene using image processing techniques [4]. The main objective in the development of the VFA technique is to provide a reliable fire sensing tool for fire detection [8] and fire scene analysis. If such analysis is performed fast enough, real-time predictions of the fire development [9-11] can be produced to help the decision making process for example for firefighting or evacuation [12].

In this paper, the primary objective is to demonstrate that, thanks to a Flame Detection Algorithm (FDA), reliable data for flame spread could be obtained and used later in simplified modelling of cable tray fire. The reliability of the flame spread data is assessed by comparing a reconstructed HRR (from such data) to the HRR measured by oxygen calorimetry.

\subsection{Flame front and extinction front measurements}

The flame detection algorithm developed in [4] has been applied to track the temporal evolution of the flame front, $r_{f}$, and extinction front, $r_{e x}$, at the level of each tray, $i$, as shown in Fig. 2. The trays are numbered from bottom up. The measurements are explained in Fig. 3 and displayed in Figs. 4 and 5.

Figure 4 shows, in the initial stages of the fire (between 40 and $80 \mathrm{~s}$ ), a very sharp increase in the location of the flame front up to $r_{f}=400 \mathrm{~mm}$, which is due to the fire plume generated by the burner of $300 \mathrm{~mm} \times 300 \mathrm{~mm}$. After approximately $120 \mathrm{~s}$, the flame front is observed to increase at lower rates. 


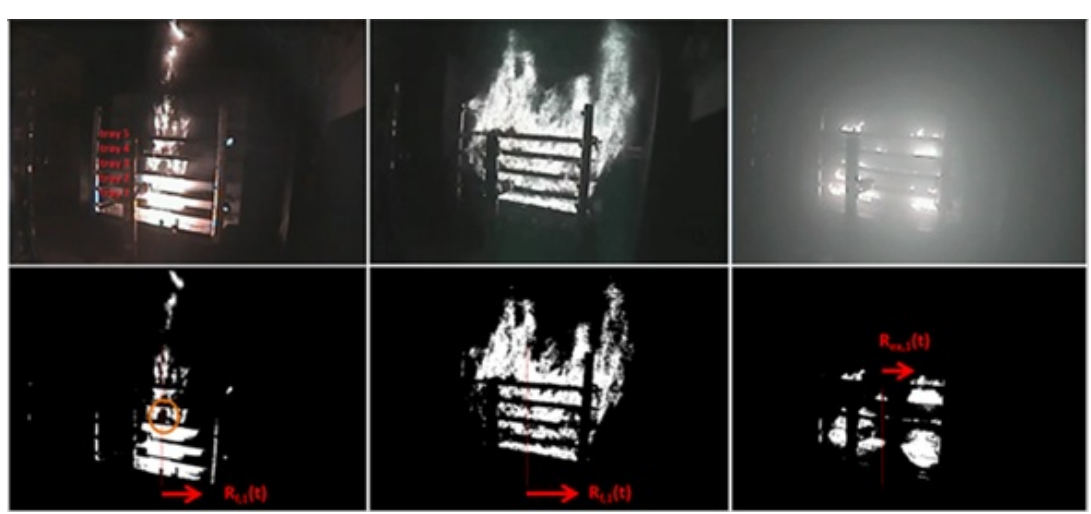

Fig. 2 Illustration of the flame detection algorithm used in the VFA performed in this work. The top images are extracted video images. The bottom ones are processed using the FDA
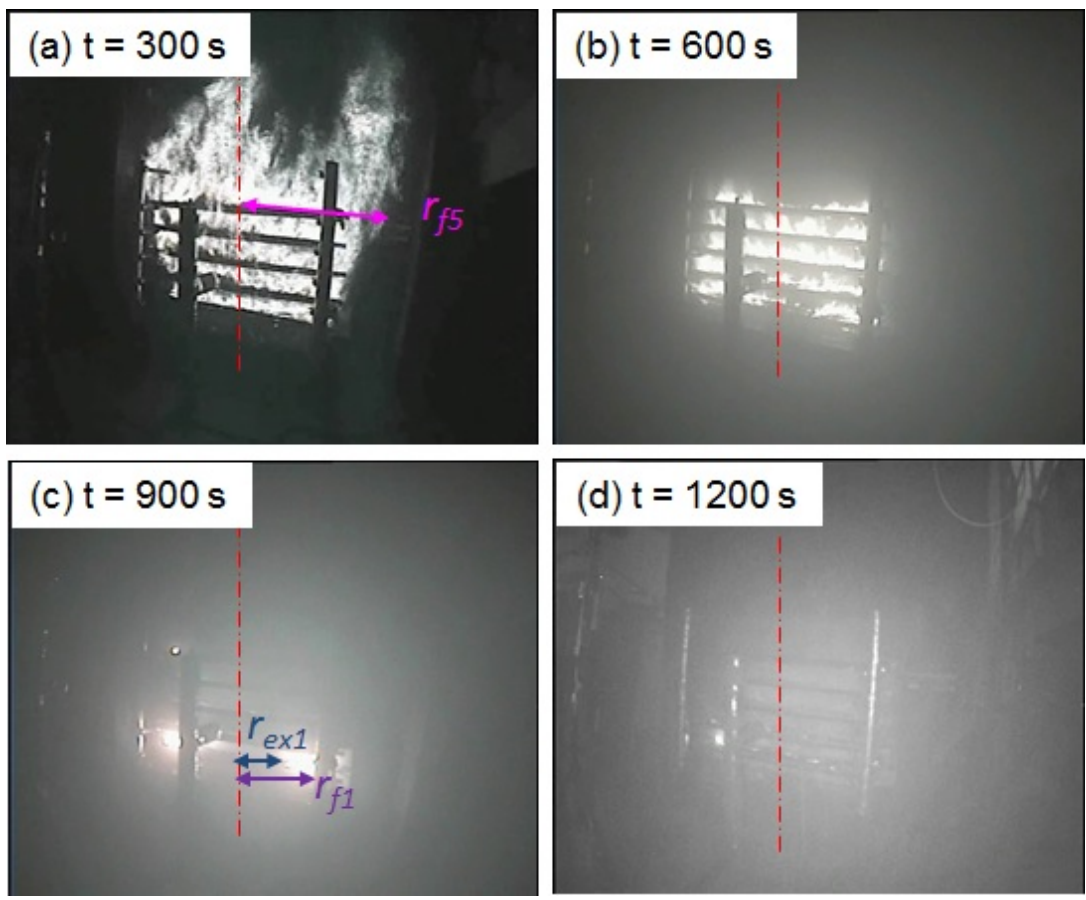
(d) $\mathrm{t}=1200 \mathrm{~s}$

Fig. 3 Time sequence of video images and illustration of the FDA measurements (The variable $r_{f 5}$ denotes the flame front at the level of the fifth tray. The variables $r_{f 1}$ and $r_{e x 1}$ denote respectively the flame front and extinction front at the level of the first tray ) 


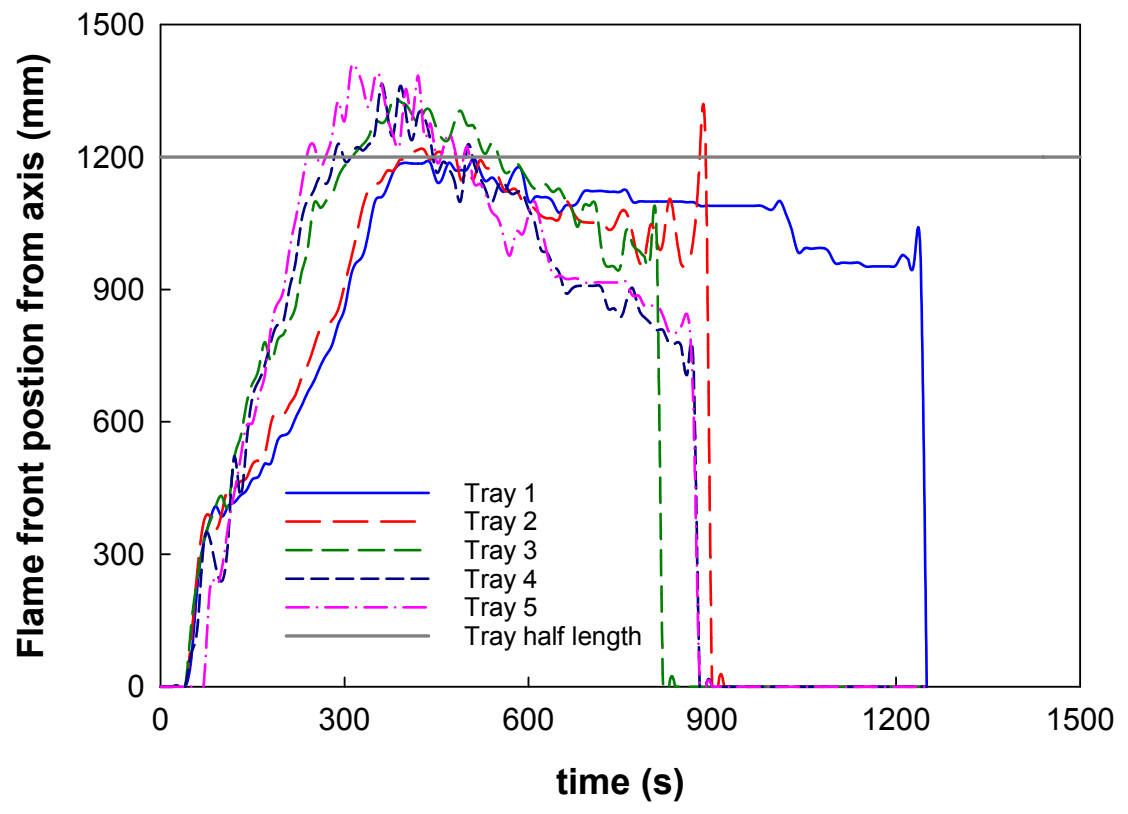

Fig. 4 Measured temporal evolution of the flame front at the level of each tray

Flame spread at the level of trays 1 and 2 is clearly lower than for the group of trays 3 to 5 . A more detailed discussion on the spread rates will be provided further in a separate section. The flame front reaches the end of all the trays at approximately $400 \mathrm{~s}$, which is the expected time for the occurrence of the HRR peak, since the full combustible load area is burning. One can clearly see that the flame front position may exceed the tray half length. This is due to the high flow rates of pyrolized fuel that is partially transported up to certain radial distance from the sides of the trays. The slight decrease in the flame front positions after $400 \mathrm{~s}$ is due to a decrease in the flow rates of pyrolized fuel and the induced change in the flame shape. The sharp decrease (after a slight decrease in the flame front position) is attributed to the fact that the extinction front reaches the flame front.

Figure 5 shows some noise in the measured profile of the temporal evolution of the extinction front. For example, the extinction front measured between 0 and $200 \mathrm{~s}$ can be attributed to holes in the flame envelope (indicated with a circle in the bottom left picture of Fig.2). A persistent extinction front is recorded first at the level of the 5th tray at approximately $500 \mathrm{~s}$. The extinction front reached the tray end for trays 2 to 5 between 800 and $900 \mathrm{~s}$. Full extinction at the level of the first tray occurred only around $500 \mathrm{~s}$ later. This can be explained by the lower spread rate for the first tray. 


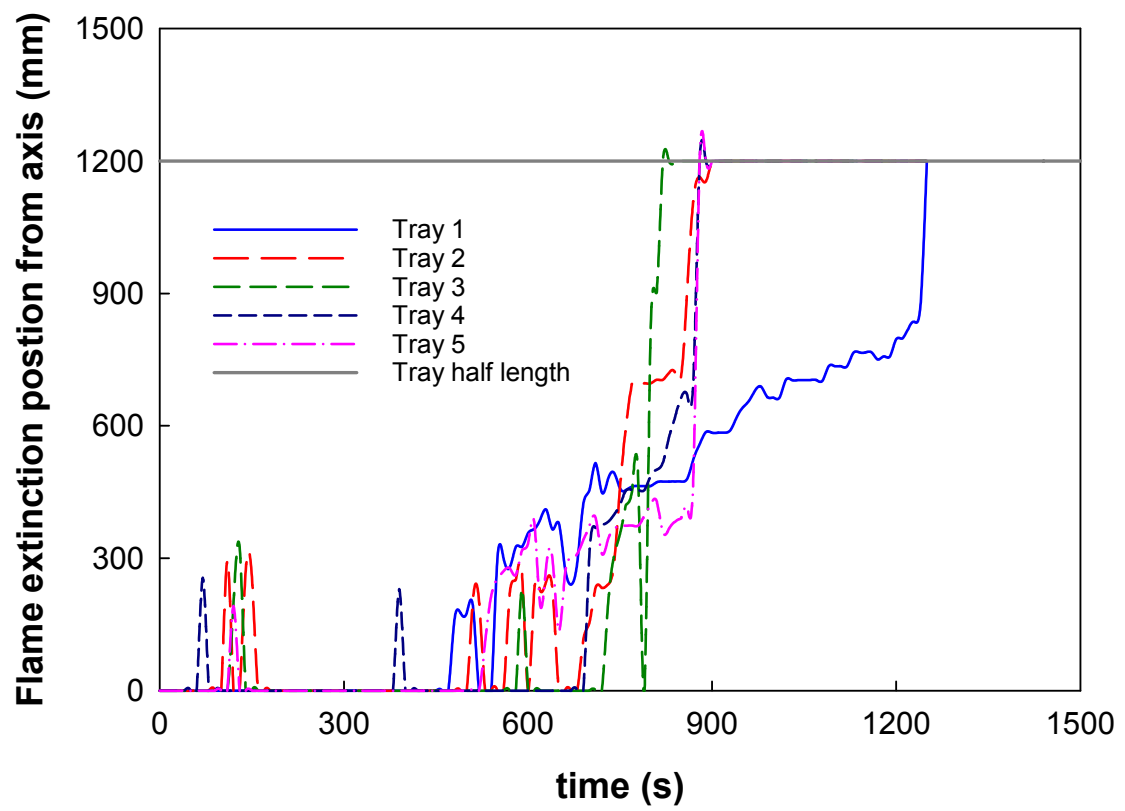

Fig. 5 Measured temporal evolution of the extinction front at the level of each tray

\subsection{HRR reconstruction}

The fire HRR is estimated as follows:

$$
\dot{Q}_{f}(t)=\sum_{i=1}^{n} 2\left[r_{f, i}(t)-r_{e x, i}(t)\right] A_{c b l}^{\prime} \dot{Q}_{f}^{\prime \prime}
$$

where $t$ is the time, $n$ the number of trays, $A_{c b l}^{\prime}$ the cable burning area per unit length $\left[\mathrm{m}^{2} / \mathrm{m}\right]$ and $\dot{Q}_{f}^{\prime \prime}$ is the Heat Release Rate per Unit Area (HRRPUA), which is assumed to be constant. The coefficient 2 refers to the fact that measurements were performed on only one half of the trays. Flame spread is assumed to be symmetric. This was not a premeditated choice but rather a constraint due to the positioning of the camera that did not allow a clear monitoring over the full length of the trays.

Cables are arranged loosely along the trays. Therefore, it is assumed that all the cable surface per unit length may burn at the same time. So, the cable burning area per unit length is calculated as:

$$
A_{c b l}^{\prime}=n_{c b l / t r a y} \pi d_{c b l}
$$

where $n_{c b l / t r a y}$ is the number of cables per tray (49 in this case) and $d_{c b l}$ the cable diameter $\left(d_{c b l}=13 \mathrm{~mm}\right)$. 


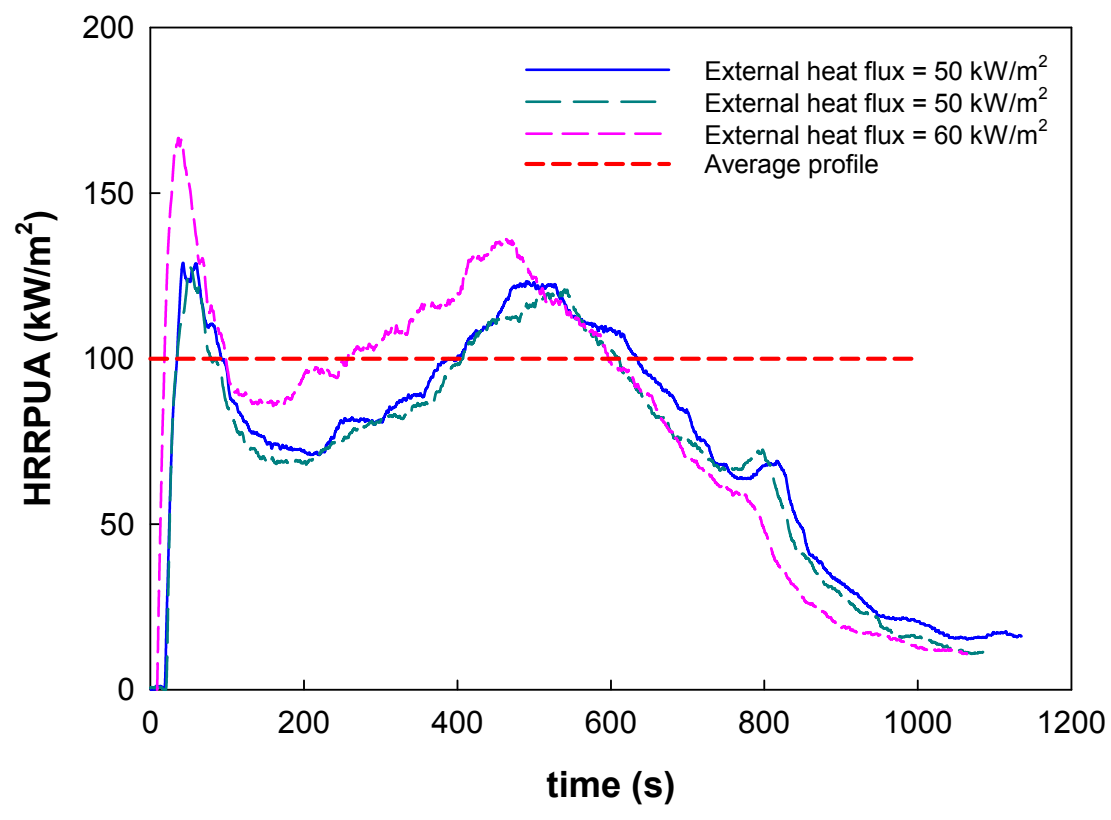

Fig. 6 HRRPUA from standard cone calorimeter experiments at 50 and $60 \mathrm{~kW} / \mathrm{m}^{2}$ heat flux (data taken from [13] and recalculated based on an exposed area computed from Eq.(3))

In Eqs.(1) and (2), it is assumed that the burning is two dimensional and that the burning area can be estimated by multiplying the cumulative perimeter of all the cables by the burning length.

The remaining unknown in Eq. (1) is the HRRPUA, $\dot{Q}_{f}^{\prime \prime}$. It is estimated by performing small-scale cone calorimetry measurements under a constant external heat flux, $\dot{Q}_{E}^{\prime \prime}$. The HRRPUA is calculated then by dividing the HRR by the exposed area. The exposed area is typically taken as the area of the sample holder $\left(88.4 \mathrm{~cm}^{2}\right)$. However, in order to be consistent with Eq. (2), the exposed area of the cables in the cone sample is calculated here as:

$$
A_{\text {sample }}=n_{\text {sample }} \frac{\pi d_{c b l}}{2} L_{\text {sample }}
$$

where $n_{\text {sample }}$ is the number of cables placed in the sample holder (in this case $n_{\text {sample }}=7$ ) and $L_{\text {sample }}$ the length of each cable, taken as $L_{\text {sample }}=$ $0.1 \mathrm{~m}$. Note that, contrary to Eq.(2) for the full-scale, only half of the cable circumference of the cables is exposed (and thus considered) in the cone calorimetry tests.

The cone calorimetry results displayed in Fig. 6 show a good repeatability for the $50 \mathrm{~kW} / \mathrm{m}^{2}$ tests and an average HRRPUA of $100 \mathrm{~kW} / \mathrm{m}^{2}$ at the 


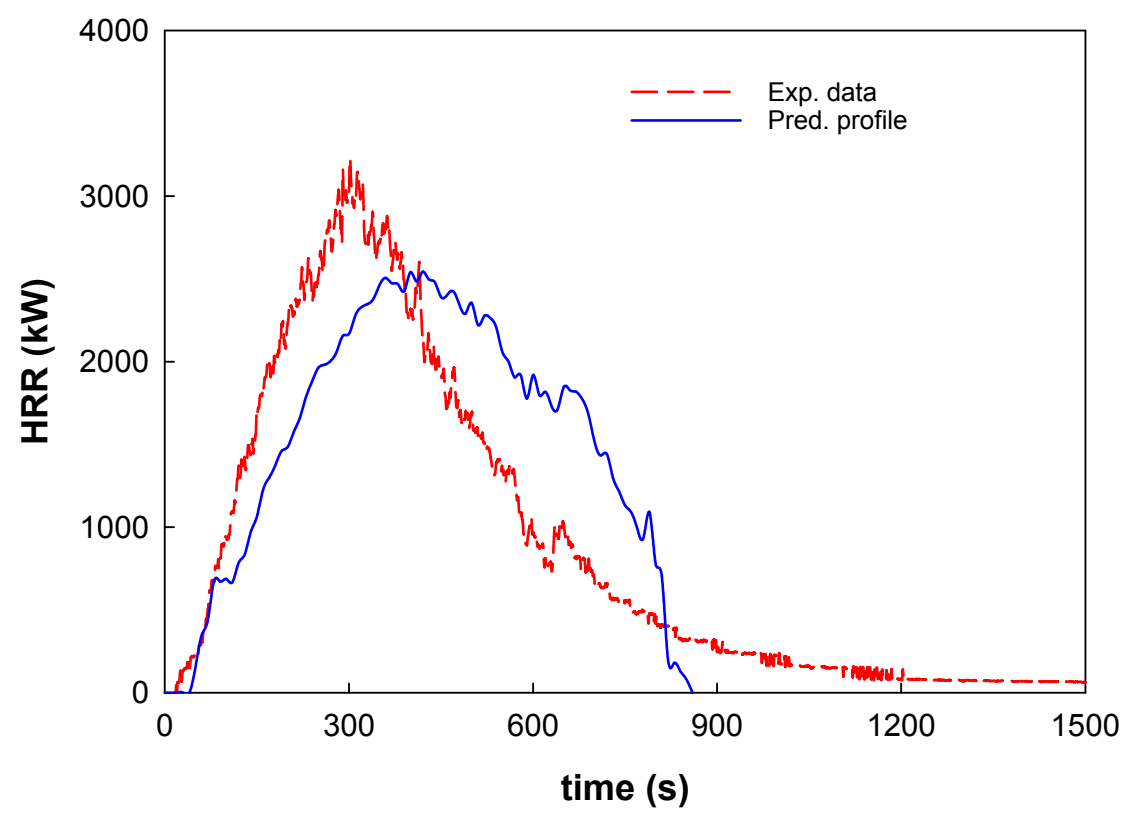

Fig. 7 Measured (using oxygen depletion calorimetry) and predicted (using VFA) HRR profiles

steady-state stage.

Figure 7 shows an overall good agreement between the reconstructed HRR profile based on Eq. (1) in conjunction with the flame spread measurements (using VFA) and the measured profile (using oxygen depletion calorimetry). As expected from the flame front measurements, the time to reach the peak HRR is overestimated by approximately $100 \mathrm{~s}$. Furthermore, the peak HRR is underestimated by approximately $17 \%$.

\subsection{Discussion on flame spread}

Spread rates The flame front results displayed in Fig. 8 show that flame spread rates vary between 2 and $5 \mathrm{~mm} / \mathrm{s}$. Furthermore, there are two distinct flame spread rates. Flame spread at the level of trays 1 and 2 occurs at an average rate of $2.35 \mathrm{~mm} / \mathrm{s}$. The average rate for trays 3,4 and 5 is significantly higher, $v_{f}=4.68 \mathrm{~mm} / \mathrm{s}$. This could be explained as the following. For the higher trays, radiation comes from all sides, whereas for the lower trays it comes rather essentially form the top. Furthermore, it is well known that the width of a smoke plume increases with height, which enhances the convective heat transfer for the higher trays and results in a larger surface area for flame 


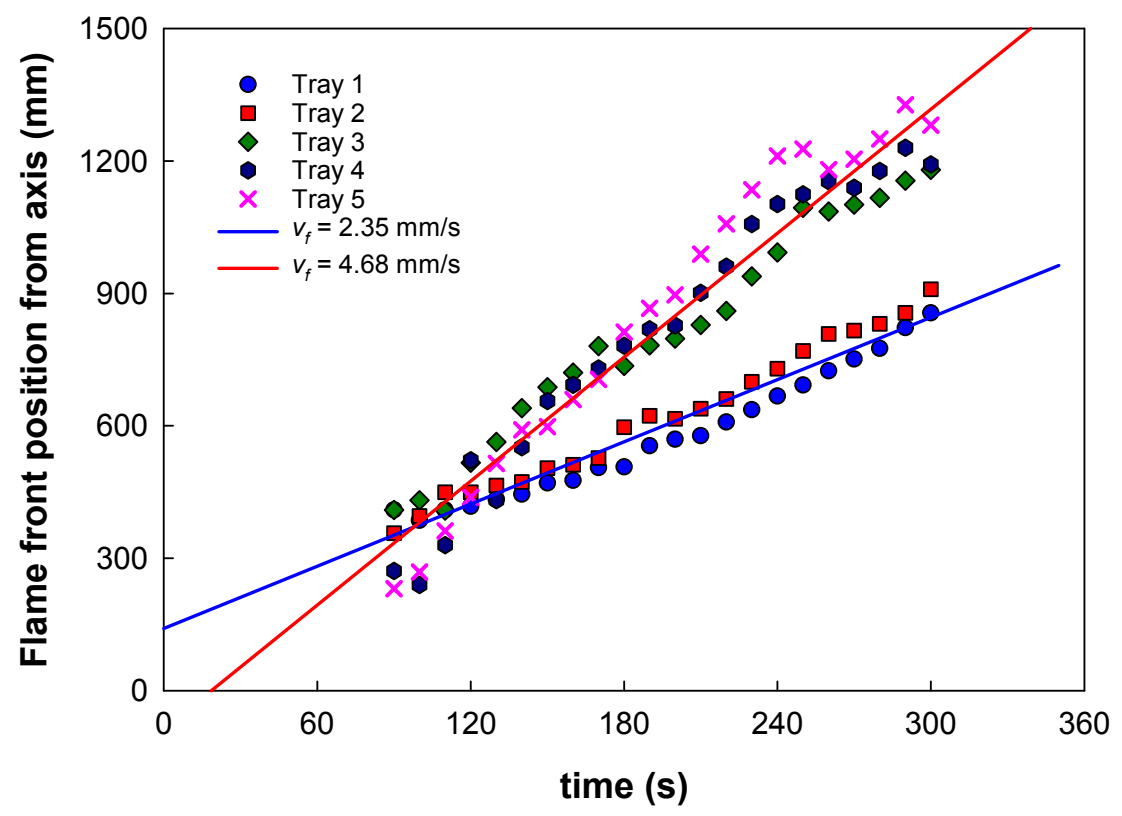

Fig. 8 Measured temporal evolution of flame front at the level of each tray between 90 and $300 \mathrm{~s}$ and corresponding estimated flame spread rates

impingement. Cables of the upper trays are more pre-heated than the ones of the lower trays, which results in higher spread rates.

Flame spread angle Figure 9 shows that flame spread could be further characterized by estimating the angle of the $\mathrm{V}$-shaped pattern produced in the configuration of interest. An analysis of the flame front positioning at three instants during the fire stage shows that the obtained pattern is not readily characterized by a V-shape. However, if one assumes that it is the case and performs a linear regression (as shown in Fig. 9), the angle $\theta$ can be estimated to be within a range of $13^{\circ}$ to $21^{\circ}$.

\section{Conclusions}

The work presented in this paper showed a detailed application of Video Fire Analysis (VFA) to a cable fire spread (CFS) scenario investigated experimentally in the framework of a large international collaborative research project, namely the PRISME 2 project. Thanks to a flame detection algorithm, important information was obtained on the flame spread process for a stack of five horizontal trays. The information consists primarily of the temporal evolution of flame front and extinction front at the level of each tray. It has been 


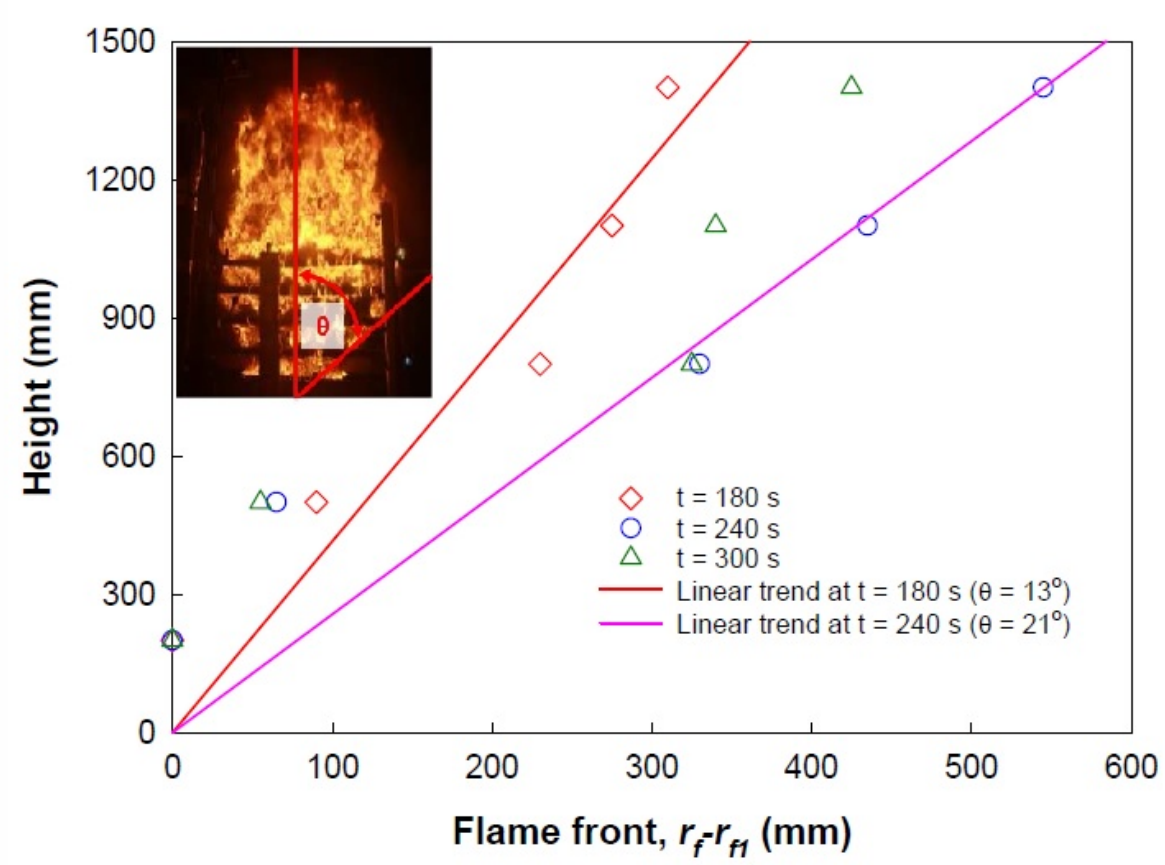

Fig. 9 Estimated flame spread angle from flame front measurements at different instants during the fire growth stage (the variable $r_{f 1}$ denotes the flame front at the level of the first tray)

shown that by processing further this data, one can obtain additional information such as: (1) the temporal evolution of the HRR profile, (2) lateral flame spread rates, and (3) the flame spread pattern (e.g., V-shape and corresponding angle). A good agreement was obtained between the reconstructed HRR profile and the profile measured by oxygen depletion calorimetry. The VFA technique is shown thus (thanks to the good HRR prediction) to provide valuable and reliable lateral flame spread data in the case of cable tray fires. The latter remain very scarce in the literature. The measurements performed in this work show that the flame spread rate can be assumed to be constant as suggested in earlier studies. However, it has been found that there was a distinct difference in the rates between the trays. For instance, for the case at hand, the spread rate in trays 1 and 2 (lowest positions) is similar but significantly lower than the average velocity for the remaining top three trays. Further investigation on the flame front positioning at the level of each tray at several instants during the fire growth stage showed that the V-shaped pattern cannot be readily characterized by a constant angle. If the constant angle assumption is adhered anyway, the value varies between $13^{\circ}$ and $21^{\circ}$ for the case at hand.

In a nutshell, the application of VFA to real-scale experiments is shown here to generate a valuable set of data (e.g. flame spread rates) for the development 
of simplified modelling that allows the prediction of the HRR from a stack of cable trays.

Acknowledgements The research carried out in this work has mainly been funded by Bel $\mathrm{V}$ through a post-doctoral research grant (contract number A12/TT/0617). The video fire analysis research was funded by Ghent University iMinds. The authors are also grateful for the financial support of the participating OECD/NEA member countries (Belgium, Canada, Finland, France, Germany, Japan, Spain, Sweden, United Kingdom) to the joint OECD PRISME 2 project. Thanks also to Prof. Simo Hostikka (Aalto University, Finland) and dr. Anna Matala (VTT, Finland) for providing us with the cone calorimetry data.

\section{References}

1. Electric Power Research Institute (EPRI), Palo Alto, CA, and U.S. Nuclear Regulatory Commission, Office of Nuclear Regulatory Research (RES), Rockville, MD (2005) EPRI/NRC-RES Fire PRA Methodology for Nuclear Power Facilities: Volume 1: Summary and Overview. EPRI-1011989 and NUREG/CR-6850. http://www.nrc.gov/readingrm/doc-collections/nuregs/contract/cr6850/v1/cr6850v1.pdf

2. Electric Power Research Institute (EPRI), Palo Alto, CA, and U.S. Nuclear Regulatory Commission, Office of Nuclear Regulatory Research (RES), Rockville, MD (2005) EPRI/NRC-RES Fire PRA Methodology for Nuclear Power Facilities: Volume 2: Detailed Methodology. EPRI-1011989 and NUREG/CR-6850. http://www.nrc.gov/reading$\mathrm{rm} /$ doc-collections/nuregs/contract/cr6850/v2/cr6850v2.pdf

3. McGrattan K, Lock A, Marsh N, Nyden M, Price M, Morgan AB, Galaska M, Schenk K (2010) Cable Heat Release, Ignition, and Spread in Tray Installations During Fire (CHRISTIFIRE), Phase 1: Horizontal Trays. Report NUREG/CR-7010, Vol. 1. http://www.nrc.gov/reading-rm/doc-collections/nuregs/contract/cr7010/cr7010v1.pdf

4. Verstockt S, Hoecke S, Tilley N, Merci B, Sette B, Lambert P, Hollemeersch CFJ, Van de Walle R (2011) FireCube: A multi-view localization framework for 3D fire analysis. Fire Safety J. 46:262-275. doi:10.1016/j.firesaf.2011.03.001

5. Audouin L, Rigollet L, Prétrel H, Le Saux W, Röwekamp M (2013) OECD PRISME project: Fires in confined and ventilated nuclear-type multi-compartments - Overview and main experimental results. Fire Safety J. 62:80-101. doi:10.1016/j.firesaf.2013.07.008

6. Audouin L, Prétrel H, Zavaleta P (2013) OECD PRISME 2 Fire Research Project (20112016) Current Status and Perspectives, 13th International Post-Conference Seminar on Fire Safety in Nuclear Power Plants and Installations (SMiRT-22), Columbia, South Carolina, USA.

7. Zavaleta P, Charbaut S, Basso G, Audouin L (2013) Multiple Horizontal Cable Tray Fire in Open Atmosphere, Thirteenth international conference of the Fire and Materials, San Francisco, USA, pp 57-68.

8. Cetin A, Dimitropoulos K, Gouverneur B, Grammalidis N, Günay O, Y.H. Habiboglu YH, Ugur Töreyin B, Verstockt S (2013) Video fire detection Review. Digital Signal Processing 23:1827-1843. doi:10.1016/j.dsp.2013.07.003

9. Beji T, Merci B, Verstockt S, Van de Walle R (2014) On the Use of Real-Time Video to Forecast Fire Growth in Enclosures, Fire Technol. 50:1021-1040. doi:10.1007/s10694-0120262-0

10. Beji T, Vertockt S, Van de Walle R, Merci B (2013) Experimental and numerical study of furniture fires in an ISO-room for use in a fire forecasting framework, J Fire Sci. 31:449468. doi:10.1177/0734904113479774

11. Jahn W, Rein G, Torero JL (2010) Forecasting fire growth using an inverse zone modelling approach. Fire Safety J. 46:81-88. doi: 10.1016/j.firesaf.2010.10.001

12. Cowlard A, Jahn W, Abecassis-Empis C, Rein G (2010) Sensor assisted firefighting. Fire Technol. 46:719-741. doi:10.1007/s10694-008-0069-1

13. Mangs J, Hostikka S (2013) Experimental characterization of the MCMK cable for fire safety assessment. Research report VTT-R-06873-12, VTT, Finland. http://www.vtt.fi/inf/julkaisut/muut/2012/VTT-R-06873-12.pdf 